\title{
A NEW INSTRUMENT FOR THE INTERPRETATION OF LAW-ESPECIALLY PRIMITIVE
}

\author{
BRONISLAW MALINOWSKI $\uparrow$
}

THE two names on the title-page are a guarantee of the value and importance of this book: Karl N. Llewellyn, a leading light in American jurisprudence; $E$. Adamson Hoebel, an ethnographer with an excellent record in field-work and theoretical contributions, especially to primitive law. The Cheyenne $W a y$ is a stepping stone and a landmark in the program of social science. It suffers from some extravagances of style and treatment which are provocative. Some of its hesitancies and failures will stimulate further research. Certain achievements are lasting and will prove of great value to social science, anthropology, and to the theory of law, primitive and crystallized.

The aim of the book is "the development of a social science instrument for the recording and interpretation of law-ways among primitive peoples" ( $p$. viii). The instrument is developed against the bacliground of the cultural life of the Cheyenne Indians. In some ways this appears to be an excellent background. "The curious and lovely Cheyenne material" (p. 289), as the authors lyrically describe it, allows them to lay bare certain aspects of primitive justice and primitive judicial process. The material is also difficult to handle: the Indians have been long subjected to the process of detribalization, to new environmental settings, to changing economic systems, and undoubtedly also to the influence of the white man's legal and political pressure. All this complicates matters and not all of the resulting tangles seem to have been unravelled.

The authors have digested the older literature, especially the worlis of George Bird Grinnell. They have by original field-work supplemented the older data with regard to the legal principles and practices of their natives. This, indeed, is "a vital phase of social life which was ethnologically terra incognita in the days of Grinnell" (p. viii).

The greatest importance of the book consists in the theory of law in general and of primitive law in particular which forms the founda-

$\doteqdot$ Bronislaw Malinowski was from 1939 until his death Professor of Anthropology at Yale University. In seminars, conducted with members of the Law Faculty, he made available to the students of the Law School his vast learning and quicl insight. The Yale Law Journal is highly privileged to publish the following pages, both for their importance to students of jurisprudence and in tribute to a great scholar and innovator. This article appeared originally in the NATrowal LAwyens GUnd RETEW for May, 1942. The editors of the Yale Law Joursal express their thanks to the Narro:tas. Lawyers Guild Review and to AIrs. A. V. Malinowslia for permission to reprint. The article was prepared as a review of The Cheyeme Way: Confict and Case Law in: Primitive Jurispradence, by K. N. Llewellyn and E. Adamson Hoebel (Norman, Olila., University of Oklahoma Press. Pp. vii, 360. \$3.00). 
tion of the treatment of Cheyenne law. The authors are fully aware that the cross-fertilization of jurisprudence by the study of primitive law is beneficial for both. In the study of communities where law is neither codified nor administered before courts, nor yet enforced by constabulary, certain problems arise which can be easily overlooked in a jurisprudence based on our own formal and crystallized systems. Why have men to obey certain rules? Why have such rules to be known by the actors, formulated, and made valid? Why is the validity of some such rules never questioned, while others seem to offer constant temptation to breach?

Such questions and cognate ones face the ethnographer who tries to formulate the principles of what in primitive communities corresponds to the process of law. The very definition of law and its relation to custom, ethical rule, the norms of manner and etiquette, are problems which must be raised and answered by the field-worker, the student of comparative jurisprudence, and the sociologist who attempts to place law in relation to social control, and social control in relation to culture as a whole.

I shall try here to state the position of primitive jurisprudence in my own terms and from my point of view which, as far as I can see, is cognate to that of the present book. The crucial problem in the study of primitive law turns round the concept of cultural determinism. Is man's organized and implemented behavior, that is culture, subject to laws in the scientific sense? Many modern anthropologists would probably answer this in the negative. So does one of the most brilliant contemporary thinkers in jurisprudence, one who has contributed greatly towards our understanding of the relation of law to culture and its processes. "Social life and social relations are . . . basically incongruous and disorderly." 1

1. Cairns, The Theory of Legal Science (1941) 53. The whole Chapter 4, "The Principle of Disorder", in which this sentence occurs, turns round the thesis that there is no such thing as an intrinsic determinism of culture. The Author suggests that "the notion that social life is essentially orderly and congruous" is due to the "mechanistic" approach of certain sociologists. "The human world is thus one of infinite complexity." "In social theory . . . order cannot . . . be assumed as part of the data." The writer's thesis is that such order as we find in human societics is due to "intentional controls invented by man." ". . . The order which exists in human society at any given time is predominantly an achieved order, an invention at the center of which is man ...." All this to me begs the question of why, and for what reasons the inventors of order invented it. In my opinion human inventions are determined by the needs of the individual and of the community. Once we agree on this, the second question arises whether the invention of order is not quite as much determincd by real conditions of human co-operation and common life, as the invention of fire, stone implements, dwellings, weapons, canoes - and indeed the "invention" of the family, marriage, authority, knowledge, magic, recreation, and religion. 
Culture, however, primitive and developed alike, is subject to the laws of physics since human bodies are first and foremost lumps of matter. Each body is an organism, alive and active and submitted to the laws of biology. Hence culture is also largely determined by the biological process within the human body and by the organic needs of man. Culture and its development again consists in technological invention, that is, in the discovery by man of natural laws and in their application to human ends. In any partial process of culture, men. organized and fitted out with artifacts, follow the rules of technique determined by natural law. These technical rules shade immediately and almost imperceptibly into rules of concerted action. Such rules carry a sociological quota and are symbolically formulated. They are partly determined by physical, physiological, and technological principles.

Imagine a primitive team of carpenters who have to construct an outrigger canoe from a $\log$ and beams, poles, and planks. They start from the point of deciding to do it, and then have to prepare the material, carry it to one spot, shape it adequately, construct the object, and then use it for determined ends. The laws of behavior, in its technical, economic, legal, moral, and even magical aspects, form an integral whole which determines the actions of every individual of the group, as well as the physical and physiological phases of the relation between man and matter. The end or purpose, the starting point, the determinisms of mechanics and hydro-dynamics, as well as of muscular and nervous energies, are integrated into a system which is neither chaotic, nor disorderly, which indeed is determined and regulated by principles open to observation and capable of being formulated.

The same could be said of any other teclnical achievement by concerted and organized action. The production of fire and of stone implements, the co-ordination of food gathering, hunting, fishing, or agriculture, are one and all determined by the task, the materials available, and the relation of manual technique to co-operative interchange of services. The structure of economics, of the normative system, of organized recreation, and of magical and religious cults is also based on the human needs which are satisfied in each such activity. Human needs in turn are not arbitrary, but are based on physiology and environment, and also on the nature of those instrumentalities, physical, social, and psychological, which constitute culture. All the fundamental categories of human behavior are subject to the intrinsic determinism of culture. And here, as in all other branches of genuine science, we shall have to remain satisfied with general principles of the fundamental and relevant: de minimis non curat lex- whether this be scientific or manmade law.

Organized human activities at a primitive or advanced level are thus first and foremost determined by the specific problems of man's physio- 
logical needs. The solution consists in technological production related to the use of the product. The social and legal rules of property, of privilege, and of duty are part and parcel of the solution of a practical problem through applied knowledge, social co-operation, and the establishment of cultural values. Cultural determinism is deeply founded in the fact that no activity at a primitive or developed level takes place without being directly or indirectly related to the basic needs of the human organism.

This indirect or roundabout solution of man's organic needs within his environment imposes secondary determinants. These can be classified into such aspects of culture as the economic, the educational, the normative, and also those pertaining to the use of language, the development of knowledge, and the exercise of religious and magical cults. The very fact that in the last quarter of a century anthropology has established general principles of primitive economics, of preliterate education, of early jurisprudence, as well as outlines of the first stages in epistemology, and the nature of magic and religion, is a proof that ctittural determinism has already been scientifically established. Human beings at all levels of development act not within a chaos, nor yet in a nondetermined, many-dimensional vacuum, but are subject to clear and specific determinants of behavior.

Another line on which the existence of order in culture can be recognized is the recurrence of typical forms of organization, that is, of institutions. The family, the municipality, the organization of kinship and clanship, age-grades, and occupational teams are universals of primitive culture. Evolution consists in a constantly increasing institutional crystallization of such specific activities as those related to economic production, distribution, and consumption; the administration of law and justice; education and politics; practices of religious cult; the cultivation of science, literature, art and music; and the pursuit of sport and recreation.

Again, it would not be difficult to make an inventory of primitive artifacts: stone implements, fire, dwellings, means of transport and locomotion, and weapons - all these exist everywhere. At any level of development the inventory overlaps almost completely from one culture to another, even as regards the main types of mystical instrumentalities. Each type of artifact determines similar techniques, forms of co-operation, rules of ownership, and systems of value. Starting from the ma* terial substratum of culture, we would find again a number of concrete, clear, and definite lines on which general and specific principles of cultural determination can be established.

Symbolism, notably in language, can be shown to fall under grammatical and syrtactic, as well as semantic categories which are universal. Everywhere we find the same parts of speech, the same structure of 
the sentence, the same uses of metaphor and abstraction, the same distinction between concrete and particular on the one hand, and general or conceptual on the other.

Minor differences occur and make the study of anthropology interesting and inspiring. Underlying such differences, however, there is the universal determinism based on the fact that man has always primarily to satisfy his basic organic needs; that in doing this by creating the artificial environment of culture, he has to act under conditions of order, continuity, predictability, and authority. Culture thus is submitted to the primary determinism of natural law, physical and physiological, and also to the secondary determinisms of its own instrumentalities.

In all this the fundamental rules of behavior defining the relations between individuals and groups re-appear once more, as an integral part of the determinism of culture. Agreements between individuals through contract; rules of conduct based on birth and status; reciprocal concatenations of duties which establish such typical relations as between husband and wife, parents and children, kinsmen and clansmen; the duties and privileges of status, rank, and authority, occur throughout and are invariably true to type.

We can thus speak about the laws of culture in the widest sense. "Law" here means in every case a generalization with predictive value, arrived at by the inductive study of various cultures. ${ }^{2}$ The existence of such "laws" of cultural process makes anthropology as a scientific stuidy possible. Its value has been proved by the increased quality of modern field-work, which under the guidance of general principles of anthropology operates with much more exact conceptions and is able to disclose the reality of primitive education, primitive economics, and primitive legal or normative processes, as well as to study the institutions of a tribe.

2. Examples of such laws are contained already in the previous argument. Those acquainted with the works of Sumner and Keller, Westermarck, Hobhuuse, Durlsheim, Radcliffe-Brown, R. IW. Firth, A. I. Richards, G. P. Murdock - to mention but a a few names - will easily supply many other cases. The large seale enterprise of digesting, ordering, and classifying ethnographic evidence, which under the title of "cross-cultural survey" is now in progress under the direction of G. P. MIurdocl: at the Institute of Human Relations, Yale University, is perhaps the most important and decisive argument in favor of cultural determinism. The present reviewer would lite to refer also to his articles: Culture, Excrc. Soc. Sctersces (1931); The Grous and the Individual (1939) 44 Axr. J. Soc 938; Man's Cullure and Mon's Behroior (1941) 29 Sigara XI Q. 186, (1942) 30 id. at 62; Marriage, Encre. Bertumial (ed. 1929); Kît:ship, id.; and Social Anthropology, id. Chapple axd Coon, Pancirles or AtisumoroloGY (1942), a recently published textbook, is perhaps the first full and well documented exposition of the science of man from the point of view of cultural determinism. The reader will find there a mine of illustrations of what the principles of cultural determinism are. 
The term law obviously means in this context something essentially different from law as rule traditionally established or promulgated, obeyed, or broken and enforced. Indeed, the laws of cultural determinism are to a large extent obeyed without ever being stated by those concerned.

Thus the distinction must be made between rules implicitly followed and rules formulated. It is clear that primitive man from the outset obeyed the natural laws of physical and biological process in every phase of his behavior. He was subject to the principles of blood circulation, of breathing, and of digestion, although he was not cognizant of them. Indeed, the more fundamental the law of nature or the law of physiology or psychology, the later is its appearance in human knowledge, hence in human statement. The primitive savage, very much like the modern man of science, refuses to see and to acknowledge the obvious.

Certain rules of technology on the other hand, and also of social conduct, had to be formulated or at least fixed in standardized practicc from the very beginnings of culture. All concerted action implies a symbolic co-ordination of movements. Rules of authority, of status, as well as the elementary rules of technique, had to be transmitted from generation to generation, hence they also were made explicit either verbally or in standardized behavior. We have thus the important distinction to make between (1) rules of cultural determinism accepted, but neither known nor stated; and (2) rules explicitly standardized and formulated in early symbolic gesture or sound.

To this distinction we have to add another. Among the rules stated and known, as well as taught and transmitted, there are again two classes. The first is automatically sanctioned by the coercion of efficiency or by the convenience of conventionality. The coercion of efficiency can be clearest seen in technological rules. Unless rules which define the raw material, its conditions, its preparation, and the way of handling it are followed, the implement will not be properly made, the fire will not be kindled, the hut will collapse and the canoe founder. Funting, fishing, or agriculture will give no results unless men know the environment and follow the techniques which embody their knowledge.

The rules of convenience can be found most clearly in the regularities and conventions which control human relations in everyday common life. From the very outset human behavior had to be regular and predictable, since it was collective or social. The time-table of daily life; the manners and conventions of common feeding, of uniform dress, of custom in walking, working, and sleeping were indispensable. Human beings have to depend upon the behavior of others. The high value of convention and uniformity in primitive cultures, and again in our modern cultures of mass production, is not a freak, but a necessity. Thus a whole set of regularities of human behavior remain outside any socially organized enforcement. In addition to these, many rules of manners, 
conventions of behavior, tricks of useful technique, material and social, once adopted prove their own utility and efficiency. There are also no temptations to break or to stretch such rules.

As soon as a rule curbs certain physiological propensities or delimits the advantages and claims of two or more parties, there enters the element of divergent interest. Thus rules referring to the distribution of food, rules related to sex, to authority, to privilege, and duty respectively; all the rules which impose more effort and less reward on a class, group, or individual for the advantage of another, have to be sanctioned. Here enter also the rules which protect life and property, and prevent bodily harm between individuals, that is, rules of criminal law. There must exist in all these cases definite codes known and accepted by those concerned. There is here always a temptation to evade, to stretch, or to break such rules. Hence disputes, early forms of litigation and of adjustment do occur at a primitive level. In the course of evolution the stretching and the breaking of law produce the machinery of law in our modern sense.

In this last sentence, the term law once again appears in two meanings: as (1), law of order, and (2), law of correction. Homonyms are a perennial source of confusion in scientific arguments. In the study of law the confusion created by the multiple meanings given to the main term has been as vicious as anywhere. In our argument at least four different meanings have made their appearance.

Law (1) is the rule of determinism. It is used here in the same sense in which "law" appears in the phrase "law of science" or "law of nature". In this context we are primarily concerned with the laws of cultural determinism.

Law (2) is the rule of conduct standardized in behavior or verbally formulated. The rules of knowledge, of technology, of co-operation, of common life, and of convention, enter into this class. The rules of primitive knowledge usually occur as imperative or, at least, normative statements, since they are formulated invariably so as to fit pragmatic contexts. They bear a strong surface resemblance to other imperatives of tradition.

Law (3) applies to rules of conduct which refer to relations between individuals and groups, delimit divergent interests, and curtail disruptive physiological and sociological tendencies. Here enter most rules of property, contract, status and authority, as well as the rules protecting human life and limb, and limiting sexual rights to well-defined social relations.

Law (4) is the specific mechanism which is brought into existence when a conflict of claims arises or a rule of social conduct is broken.

Let me first state that this is not meant to be a full classification of all rules and norms of behavior, knowledge, or belief. Some distinc- 
tions, especially with reference to magic and religion as contrasted with knowledge, would have to be made in a fuller analysis. The aim of this little list is to show clearly that some of the ambiguities must be eliminated before jurisprudence can be made safe from its own verbal confusion. The differences indicated are real and the categories distinct. The concept of Law (1) is clear - if there is a scientific approach to culture, such laws must exist, for science begins with the formulation of general principles. The distinction between Law (1) and Law (2) consists in that the laws of the science of culture can only be formulated by the student, while the principles of Law (2) are formulated by native tradition. Native tradition consists of doctrines, principles of knowledge, beliefs and mythologies. This body of primitive lore becomes applied to behavior in the form of rules of conduct. We might speak of cultural determinism as, on the one hand, defined by the scientific observer, and, on the other, interpreted by the natives and applied by them to their own behavior. Law (1) contains the principles of determinism stated by the observer, Law (2) the principles of conduct derived by the natives from their own traditional body of doctrine.

The interest of jurisprudence begins with the distinction between Law (2) and Law (3). The rules of Law (2), in so far as we find in them an automatic sanction, are not subject to the tensions and the conflicts which make the maintenance of Law (3) invariably a dynanic process. They lack above all the element of sanction as a social reaction. Law (3), on the other hand, corresponds definitely to Lave as we use the term in our own society. Rules which delimit claims and interests have to be known and clearly stated. Their maintenance is a matter of concern to those whose claims and interests are involved. Laws of this type are often positively sanctioned, that is, strict observance is rewarded, quite as much as inadequacy and breach punished.

I suggest, however, that it is the distinction between Law (3) and Law (4), that is, the law of order and law maintained, as opposed to the retributive and restitutive social action, which has to be emphatically stated. The two are in a way exclusive of each other. When we speak of a law-abiding community, we mean Law (3). When we speak that "law" has been brought into action, we mean Law (4). Law (4) comes into being when Law (3) ceases to work. As long as Law (3) reigns, there is no room for Law (4).

The two realities, order and the mechanisms of its re-establishment, are clearly related. They are also in a way exclusive of each other. They are indeed complementary in one way and exclusive in another. To identify them, to use the same word indistinctly and confusingly so as to cover the two processes, both "maintenance" and "restitution", is a terminological confusion. 
Our main plea, therefore, is that in all arguments of jurisprudence the term law should be used with a clearly defined meaning. This can easily be achieved by a contextual or adjectival distinction such as "law" of cultural determinism", "law or rule of native conduct", "law of order and maintenance" and "the mechanisms of law when breach occurs."

Returning to the present book, I think that the position of the authurs is in principle cognate to the outline here given. In discussing the concept of claim the authors state that "it takes the form of an allesterl right or rightfulness which tends inevitably, in the context of any particular group or Whole, to get itself set up as being properly a part of the way that Whole is going around, or of the way it ought to and is about to go around, if the claimant be successful" (p. 274). This, I take it, means that every specific law - and here law must be understood as an element of order and a part of concerted action - has to he studied in relation to an organized system of activities, that is an institution. To study the claims within a family or a local group, or a military society, we must know the structure and the working of such an institution.

The positive aspect, that is the need of understanding why laws work before we proceed to their breach, is also clearly stated. "The members of the group, working within its order, then either manage so to handle divergent claims as to keep the 'group' still the group, or else the lawjobs fail to get done, and the group explodes or dribbles apart, or dies" (p. 274). This again I interpret as a sound rule of method. Every element of primitive law, every claim, is determined by the need to maintain the identity of the group. This, however, is not merely a formal principle. A group like the family has a definite purpose to achieve. The same is true of a team of buffalo hunters, of a military society, of people who combine for any pursuit, economic, religious, or administrative. Hence, in the above quotation I would like to make one correction. "The group explodes or dribbles apart, or dies" not merely because the law-jobs fail to be done. The law-jobs have to be done, because this is an indispensable condition for the achievement of the real tasks of each group. Law is not an end in itself, but an indispensable instrumentality for the achievement of the real, ultimately biological ends of human activities.

The primary source, therefore, of social constraint, which as a sanction distinguishes law from other rules, lies in the organization of the groups for the achievement of definite ends. In other words the sanction of primitive law resides in the constitution of purposeful, organized, and effectively working systems of human activities. The rules which are fundamental to the working of such institutions as the family and the clan, the military society, the age-grade, the tribe, and the occupational team have to be maintained. As Llewellyn and Hoebel repeatedly 
state, any failure to maintain the rules makes an end to the institution. An end of an institution again means that a number of essential tasks fail to be done. Extinguish the family, and reproduction, nutrition and kinship are finished. Extinguish the municipality and there will be no co-operation nor exploitation of the environment. The law of order and of co-operation is thus, at least implicitly, recognized by the authors as one of the primary factors in cultural determinism. The fundamental rules of marriage and kinship, of property, inheritance, and succession, of co-operation or agreement, are as indispensable to the effective success of an activity as the tools used, the food consumed, the participants who work, and the values which guide them.

It is clear that this approach to primitive law and law in general is wider than that of the lawyer who is merely a craftsman in our modern legal system. The lawyer qua craftsman must primarily be interested in law breaking, in guiding of the clients' conduct so as to prevent punishment if not breach, in framing contracts and effecting compromises. All this brings about his professional involvements and his financial emoluments. The sociologist and the ethnographer on the other hand must primarily be interested in the working of social control, that is, in the maintenance of order. I would like to suggest that today jurisprudence must also take the deeper as well as the more comprehensive view of the problems of law.

The lawyer of yesterday was as a craftsman perfectly justified in treating his subject as a self-contained universe of discourse, since change in the constitution of human societies and consequently the change in Law (3) were almost imperceptible. Under such conditions law codified or statutory, law customary and given in the precedent, could be treated on the principle of status quo. The whole work of courts, judges, and counsel, that is, Law (4), moved within a well established reality which changed but little, and the foundations of which could be taken for granted. The lawyers of the older generation could, like the venerable surgeons and physicians of yore, carry on their trade, accepting traditional data as something which need not be constantly revised.

When, however, the whole foundations of a craft or a practice, which is or ought to be an applied science, move and change in a well-nigh revolutionary manner, the relation between the craft and its doctrine, and the relation between that doctrine and the underlying reality, become a problem and an imperative problem at that. Thus today the practicing physician or surgeon has constantly to be concerned with new discoveries more or less revolutionary, and the craft or applied science of medicine cannot disregard its wider contexts of pathology, physiology, bio-chemistry, and even physics. 
The reality again to which modern pathology and even physiology refer is not static. The concentration of human beings in large cities, the nervous strain of modern life, certain types of labor in mines, factories, and tropical climates have created new environments for the human organism, new diseases, and new needs for hygiene and preventive medicine. Medical practice, therefore, has to follow the changes in medical science and this again constantly has to readjust to new needs of human organisms working under ever-changing conditions of strain and stress, and new dangers of infection.

In our modern world law also changes in consequence of new legal doctrines and theories, which in turn have to follow the new realities of culture. The industrial revolution with its needs of factory laws, trade union charters, the organization of trusts and the need of limiting these, has contributed towards our theoretical as well as practical insight into the nature of law. Every political revolution creates new theories and new conditions of law; Napoleon's code, the German Bürgerliche Gesetzbuch, the new constitutions of Russia, of Nazi Germany, and of Fascist Italy are examples. Law is but a part of social and cultural engineering. Today the questions about the limits of legislative action, about its relation to political force and economic efficiency, about its ability to create new types of man and new types of culture, are as practically cogent as they are theoretically illuminating.

Law does not work any more within a ritual, almost hieratic atmosphere of traditional quiescence. Law has been often used as an instrument of legislative omnipotence. There was an attempt to make a whole nation sober by law. It failed. In Nazi Germany a whole nation is being transformed into a gang of bloodthirsty world-bandits through the instrumentality of law, among others. This, we hope, will fail again. The Italian dictator is trying to make his intelligent, cynical, and peaceloving people into courageous heroes. The fundamentalists have tried in some states of this Union to make people God-fearing and bibliolatric by law. A great communistic Union has tried to abolish God, marriage, and the family, again by law.

The question, therefore, whether law is omnipotent is as important to the modern jurist as it is interesting to the sociologist. There are limits to the lawmaker. These result from the relation between law and the existing order in society. To study this relation is, in my opinion, not only the central problem of the sociology of law, but also of the lawyer's own jurisprudence. We must have juridical planning quite as much as we now have planned economics, planned politics, planned education and planned cultural regimes. Planning in itself, as we know from engineering, banking, and education, need not become a vice or a danger. Doctrinaire planning, the planning on lines of crude and partisan visions such as we find in totalitarianism, becomes a vice 
and a peril because it is done without any consideration given to the realities of human culture and human nature. The clearer our recognition that law is a system of principles which are deeply founded in the working of human culture and human society, the sounder will be our general jurisprudence and the better will it be able to assist the creation and the administration of a working social order.

To take but one concrete example: the creation of collective security in our future world is the very prerequisite of the survival of culture. What must be the nature of such international law that it nay work and solve our problems, instead of complicating them and lending itself to partisan abuses? The problem cannot be solved by the application of precedent, for this does not exist. Nor can we have recourse to any old doctrine borrowed from Plato, Aristotle, Machiavelli, or Grotius. The foundations of the future international law of collective security, collective prosperity, and collective interchange of universally human services will have to be built on order, and on the vision of what must come. We have already, in spite of all its deficiencies, a social science and a knowledge of culture strong enough to supply us with such a vision. Sloth, skepticism, and cynicism are out of place in a world menaced by the catastrophe of final extinction.

I am convinced that the jurisprudence of the future can receive great help from the contributions already made to the theory of primitive law, including those of the present book. American students in the last generation under the leadership of Cardozo and Pound, Holmes and Brandeis, Hohfeld and Cook, have advanced the state of affairs by the important distinction between "law in action" and "law in books". To this I would like to add the other distinction, perhaps even more important; between the law of order, that is the law as it is practiced in a society, and the mechanisms of sanctions, retributions, and restitutions, that is the organized and institutionalized system of professional law; the distinction, in short, implemented already in the concepts of Law (3) and Law (4).

The study of primitive communities brings both distinctions very clearly to the fore. Where there are no books, we have only law in action. The careful study of primitive law in action, however, brings us also directly to the second distinction between law of order and the mechanisms of healing the breach. The field-worker soon discovers that while breaches in primitive communities occur occasionally, the distinction between "keeping the law" and "breaking the law" is not so easily established in a community where there are no codes, courts, and constables.

Within one household the ethnographer observes a state of well-nigh perfect peace and harmony. This may be due to the full and general conformity to customary law, observed by all the members. It may be 
due to the fact that the man in authority is strong enough to keep the order of his own privileges and prerogatives so well in hand that not even a protest is ever heard. In other households there may be constant squabbling, recriminations, and even outbursts of anger and quarrelling. This may be due either to a member abusing his or her position or to an even balance between a few bad-tempered people.

The ethnographer, however, has some checks and can construct his criteria. Public opinion within the local community provides him with definite legal commentaries. The rules of what ought to be done and the partial deviations from these rules can be ascertained. The principles of what constitutes the correct relation between husband and wife, parent and child, one household and others related to it, are easily ascertained and form part of tribal tradition known to everybody. Marriage law, family law, and kinship law exist in every tribe. The ethnographer may spend a couple of years in the community without ever meeting a real "trouble case", or a serious breach of tribal law. At the same time he discovers that the maintenance of law is never a matter of yes or $n 0$, that it is not an all or none reaction. It is a dynamic process of constant struggle and readjustment. This of course applies to all other institutions - the municipality, the clan, the hunting, sailing or fishing team.

The ethnographer is thus compelled to study the working of the rules and principles of tribal law or custom under the microscope, as it were. He cannot even discover and formulate them, unless he observes at close range the battle of conflicting claims, the working out of a compromise which invariably tends to conform to the general statement of the rule as this is found in tradition. He also discovers why this is so. $\mathrm{He}$ can ascertain and state that the claims as between husband and wife, chief and subject, clan leader and other members, are related to what these people do together and what they have to contribute, one and all, to the concerted actions, as well as what they receive as reward of their contributions.

In some cases and in certain cultures the coercion of force enters as an effective factor. We have such institutions as slavery, serfdom, tyranny, and exploitation by secret societies or privileged groups. Yet even here, a further analysis discloses that the organization of force and oppression is related functionally to such phenomena as the military constitution of the tribe, the recruiting of the slave class by inter-tribal wars, and other general principles of cultural orientation which make force possible within and necessary without.

The anthropological approach to law reveals better perhaps than any other that the law of order, the principles and rules kept because they are intrinsically related to cultural determinism in general, constitutes a legitimate subject for study. The whole domain of social control, as this has been named by Professor E. A. Ross, imposes itself on the 
work of the ethnographer and on his cogitations in jurisprudence, as strongly as it seems to have been alien and unpalatable to the lawyercraftsman of the past and even of the present. This latter invariably thinks, of law as that which starts when the juridical machinery has to be mobilized.

The jurisprudence of the future, I maintain, will have to accept the anthropological position, that is study Law (3), the law of order and maintenance, the law which is positively primed and baited, as well as Law (4), that is the more or less organized coercive reactions of a community which are set in motion when a rule is broken definitely and conspicuously.

I feel it best to state my own position in my own terms, although I think it largely corresponds to the point of view which underlies the work of Messrs. Llewellyn and Hoebel. To justify this extensive monologue I would like to say that the authors perhaps have not quite clearly stated the background of their own theory.

Thus among other points they hardly have done justice to their own scholarship. In a book as ambitious and as important as the present one, it might have been well to sum up, however briefly, the contemporary position of ethnographic jurisprudence, and to indicate the place which the present contribution claims - and, as this reviewer would like to add, justly claims. We find no bibliography of ethnographic literature, no summing up of the several points of view to which the present book is an excellent corrective.

The writers somewhat surprisingly declare that "effort after effort at synthesis of the social disciplines over the past ten years has made worth-while headway in all phases, except that of integrating lawstuff with the rest" (p. 41). This might lead the reader to suspect that the writers have not heard about such contributions as Lawe and the Social Sciences by Huntington Cairns, (1935); or William A. Robson's Civilisation and the Growth of Law, (1935); or An Introduction to the Sociology of Laze by M. S. Timasheff, (1939); or that they underrate the work of Roscoe Pound; of L. Petrazhitsky; of H. Kelsen; of G. Gurvitch; of E. Ehrlich - to mention only a few outstanding names. ${ }^{3}$

I find also some misgivings about the style in which the book is written. In many ways it is magnificent, inspiring, candid, and attractive. It carries the reader along, it compels his attention, and all its extravagances and involutions are clearly a matter of deliberate pur-

3. Both authors are among the most erudite scholars in past and present jurisprudence. See for example, Llewellyn, The Theory of Legal 'Science' (1941) 20 N. C. L. REv. 1 , in which the writer devotes special attention to the recent book by Huntington Cairns, already quoted. He also gives an excellent digest of the recent theories of jurisprudence. 
pose. With all this, the style remains cryptic. This might have been easily remedied if, in relation to certain crucial passages where fundamental concepts are defined or a new and original position talien, the writers had given, after their racy and inspired phrasing of a brilliant idea, a sober translation into ordinary and accepted language. This is how the cardinal concept is defined: "Law has as one of its main purposes to make men go round in more or less clear ways; law does in fact to some extent make men go round in more or less clear ways. Law purposes to channel behavior in such manner as to prevent or avoid conflict; and law does in important degree so channel behavior. Without the purpose attribute, law is unthinkable; without the effect attribute, law cannot be said to 'prevail' in a culture, to have 'being' in it" (p. 20). Now from this passage I am not able to decide whether the Authors use the term law in this context in that sense which we labelled Law (3), or as Law (4). In following the text we come upon such phrases: "Law has the peculiar job of cleaning up social messes when they have been made. Law thus exists also for the event of breach of law and has a major portion of its essence in the doing of something about such a breach. . . The nature of law, moreover, is such that if a particular type of result is understood to follow on breach, it is likely not to be long before any other result, especially any graver or more severe result, is felt as non-law, or even anti-law" (p.20).

These passages introduce even a greater uncertainty in the present reviewer's mind. The expression "cleaning up social messes" is picturesque, but lacks precision. The adverb also leads us to suspect that law is not merely an instrument for that socially hygienic and prophylactic activity. What is its other role then? The authors remain silent.

If I had to express my preference on the several contributions of this book, I should choose Part III, Chapters X and XI, which contain a theory cognate at least to the one which I have tried to summarize above. Yet here also sentence after sentence could be quoted in which new words, original and startling - at times what appear to me excellent neologisms - are introduced, yet without any guarantee to the reader that he translates the meanings correctly.

- Let me quote one paragraph which I think contains some very important ideas: "The dynamics which generate a legal order, which keep one going, and which produce change in one, have two main aspects: drift and drive. Drift is the relatively impersonal and unnoticed lumping of behavior into belts around semi-lines which come to interlock, together with the further relatively impersonal and unnoticed shifting of the 'centers' of such belts. Drive, on the other hand, is individuated and personal. Moreover, it takes on of necessity a conscious aspect in things legal, if and whenever it meets with challenge" (p. 278). 
Here, I think, one of the most important problems of jurisprudence is stated: the distinction between the traditional growth of custom and rules, on the one hand, and the dynamic interests of individutals and groups, on the other. It is the very problem with which the jurisprudence of the future will have to deal, and one which the ethnographer is forced to face in his field-work, as well as in all his theoretical inquiries. Yet here once more it would be difficult for me to keep this passage for future quotation, or to use it as a statement of first rate authority of a point on which I am fundamentally in agreement - or so it appears to me. For really I still am not quite certain what "drift" and "drive" are, nor can I completely place the "belts", the "semi-lines" - indeed I am completely puzzled why these "semi-lines" come in, and I am unable to visualize a semi-line, especially when it comes to interlock.

And now I come to the one point on which I feel that the authors have failed to do full justice to their theoretical intentions. In my opinion they are clearly aware of the necessity of treating the problem of law against a background of cultural determinism. They also are fully aware - or so it seems to me - that the maintenance of law and order, side by side with breach and mending, is an essential problem of jurisprudence. If I read rightly the arguments of pages 273-309, there is no doubt at all that Llewellyn and Hoebel are as interested in the working of Law (3) as an instrument of order, as they are in the study of Law (4), as the means of "cleaning up social messes." Yet throughout the book the "messes" predominate. Thus in Chapters II, "A Theory of Investigation", and III, "Primitive Law, and Modern", we find an almost exclusive stress on the study of Law (4) as a consequence of breach. They state and re-state that the analysis of "trouble cases" and "social messes" is the royal road to the knowledge of Cheyenne tribal law. "Trouble cases . . . are . . . the safest main road into the dis. covery of law" (p. 29).

The material on which the arguments are largely based are fifty-three trouble cases - a magnificent record for the one aspect of the problem, but not sufficient to make us understand the full picture. Most of these trouble cases incidentally refer directly to criminal acts. The exclusive consideration of Law (4) does not allow the authors to answer the extremely important question, as to whether civil law is as fully developed among their Indians as is criminal procedure.

In the treatment of "Marriage and Sex" we find some excellent passages, especially at the beginning of the Chapter (Ch. VII). Yet here also the substance of the marriage relations, sexual, economic, parental, and co-operative, cannot easily be reconstructed from the trouble cases given, since these almost exclusively refer to certain difficulties and imperfections in the legal transactions concerned with the 
marriage contract. The analysis of property and inheritance is equally disappointing, insofar as it does not give us any clear idea of the economic basis of Cheyenne life. We are told that property and land did not play a large part in the legal system, but I was unable to find what objects had to be owned, how they were owned, and how they were handled. With the sentence, "contracts which are never broken and almost never bargained over are not subjects for clear law" (p. 229), I cannot agree. The law of contract is law, whether it is broken or not.

These criticisms might appear captious. I would like them to he constructive. This book is excellent. It cries out, however, for a second volume on Cheyenne law in which I would hope for additional data. I would also hope that some of the cryptic passages of the present book: might be translated into the plain, conventional English of social science at its best, an English of which both Llewellyn and Hoebel have proved themselves masters on other occasions.

I think that in the postulated second volume we ought to have a full outline of the cultural background of Cheyenne society as a whole. The writers frequently refer us to the two volumes of Grinnell. Yet in Grinnell's time, not only primitive law was terra incognita, but also such subjects as economics, social structure, the concept of institution, and the modern theory of culture and social organization. The facts referring to most of these problems were under Grinnell's observation and may be found in his books. A competent digest, a clearly analyzed restatement of Cheyenne culture as Grinnell saw it and lived it, would be a great contribution. Since Llewellyn and Hoebel are so eminently qualified to make it, we might feel justified in asking them for this gift.

The modern functional anthropologist fully recognizes the historical element, that is, the importance of culture change. The Cheyenne have changed their habitat three or four times as between the days when we first hear about them living in "the woodland lake country of the upper Mississippi Valley"; then moving "at the beginning of the century past to an effective adoption of the new horse culture and buffalo-hunting economy of the Plains tribes"; then being pushed again into new reservations and subjected to a type of life which the authors might have made a special effort to observe through the new methods of culture, change field work. The authors claim that their data are "arranged not on a flat time-plane, but against the moving time-perspective of the culture and the individual life" (p.ix). This promise, however, is not fully redeemed. Even plain time references are seldom to be found, and occasionally only do we find some information in the case stories which allows us vaguely to assess the integral conditions under which certain events happened. If we had one or two consistent cultural backgrounds, brief but filled in on such relevant points as the economic foundations, 
the amount of political independence, the administrative influence of white government, the degree to which educational, missionary, and trading agencies had encroached - then the historical perspective could be carried through consistently and adequately.

All this might be dismissed as a counsel of perfection. So it is very largely. The book is of a quality which makes us ask for more, satisfied and delighted though we are with the present contribution. Most of the criticisms here proffered are due largely to the fact that the present reviewer feels strongly identified with the position taken by the writers. Even those who might regard the present book as "a major trouble case in modern social science", will profit by reading it, struggling with it, and clarifying their own ideas. I am convinced that the sound and fruitful position taken by the authors is essentially correct. I hope that it may be amplified especially with reference to the inclusion of the law of order, the law as it works, that is the law which lives in the community, and not only that law which is administered against the law breakers. The book as it stands is as valuable in provoking some critical reactions, as in its fine achievements and its fundamental contribution to legal theory, to ethnography and to the study of primitive normative systems. 